Proc. Indian Acad. Sci. (Earth Planet. Sci.), Vol. 94, No. 2, July 1985, pp. 139-145.

(C) Printed in India.

\title{
Global temperature changes: relative importance of greenhouse constituents of the atmosphere as calculated with a 1-d radiative-convective model
}

\author{
$M$ LAL and K C S RAO \\ Centre for Atmospheric Sciences, Indian Institute of Technology, Hauz Khas, New Delhi \\ 110016 , India
}

MS received 11 April 1984; revised 9 November 1984

\begin{abstract}
Most modelling endeavours concerning the $\mathrm{CO}_{2}$-climate problem address only the question of the climatic response to increasing atmospheric carbon dioxide, while the amounts of other atmospheric gases remain fixed. But associated changes, either climatologically or anthropogenically induced, of minor atmospheric constituents can also be of significance in producing a substantial global warming. We have analysed the climatic response to changes in a number of atmospheric trace gases as they may enhance or counteract $\mathrm{CO}_{2}$ induced warming if their abundance should change. A comparison of the increase in equilibrium global-mean surface temperature due to plausible changes in the concentration of several trace gases in the atmosphere based on our calculations with a one-dimensional radiative-convective model is presented in this paper. Our results indicate that roughly $35 \%$ of global surface warming could be due to changes in trace gases other than $\mathrm{CO}_{2}$ and water vapour. The possible climatic consequences of the ongoing anthropogenic changes in the minor constituents of the atmosphere are also discussed.
\end{abstract}

Keywords. Global temperature changes; atmospheric carbon dioxide; trace gases; 1-d radiative-convective model; anthropogenic changes.

\section{Introduction}

One of the basic processes for determining the influence of radiation factors on climate is the greenhouse effect of the atmosphere. It is well recognised that the thermal structure of the earth's atmosphere is affected by the presence of water vapour and carbon dioxide. The main radiative effect of atmospheric carbon dioxide is through absorption of upward infrared radiation and re-radiation at the local temperature; this blanketing leads to an increase in surface temperature, the so-called greenhouse effect. The atmosphere also contains a large number of minor trace gases which can have a significant effect on the atmosphere's thermal structure because they have strong absorption bands within the 7-14 $\mu \mathrm{m}$ atmospheric window. The concentrations of atmospheric trace gases such as nitrous oxide, methane, ammonia and freons etc., have undergone substantial changes during the last few decades under the influence of anthropogenic effects e.g., intensive use of organic fertilizers, fuel burning etc. As such, the prevailing hypothesis that the origin of current and possibly future climatic changes can be attributed exclusively to variations in carbon dioxide content of the atmosphere is a simplification of reality.

To gain some perspective on the greenhouse effect of a selected list of minor trace gases together with that of atmospheric carbon dioxide and water vapour, we have calculated the changes in radiative heating of the earth-troposphere system and surface 
temperature for a two-fold increase in each of these constituents. For this purpose, we have employed the one-dimensional radiative-convective model of Ramanathan (1981) with a few modifications: (i) the model's boundary layer thickness is changed to $100 \mathrm{~m}$ from its original value of $40 \mathrm{~m}$ to account for vertical mixing and surface exchange processes more effectively; (ii) our model has a moist adiabatic lapse rate in the convective region rather than a fixed lapse rate. As shown elsewhere (Lal and Ramanathan 1984), this causes the equilibrium surface temperature to be less sensitive to radiative perturbations and both surface and tropospheric warmings due to the greenhouse effect are better resolved; (iii) the radiative treatment of various minor gases have also been included in the model. Although the model excludes horizontal transports and a number of other mechanisms, it serves as a convenient tool for comparing the relative importance of different radiative perturbations and provides a first order estimate of the assumed perturbation on globally-averaged thermal structure.

Our primary objective in this study is to compare the relative contribution to global surface warmings of several atmospheric trace constituents in a coherant manner and elucidate their role in climatic changes.

\section{The Model}

The model used here in its simplest form is a variant of the fixed relative-humidity, onedimensional radiative-convective model of Ramanathan (1981). It represents the global and annual mean thermal structure of the atmosphere at equilibrium. For an assumed initial atmospheric composition, global mean surface albedo and initial global mean vertical distributions of temperature and clouds, the solar and thermal flux divergences averaged over clear and cloudy fractions are computed at 16 unequally-spaced altitudes covering the lowest $54 \mathrm{kms}$ of atmosphere. The model has a boundary layer whose thickness is taken to be $100 \mathrm{~m}$ and all of the boundary layer variables are defined at the layer mid-point. The ocean has two layers and the uppermost oceanic mixed layer $(50 \mathrm{~m})$ exchanges energy with the atmosphere through the diffusion process. It is assumed that at the lower boundary of the ocean $(500 \mathrm{~m})$ no heat flux exists. The model atmosphere has four diabatic heating processes, viz., solar radiation, longwave radiation, vertical eddy heat flux and latent heat flux, of which the vertical eddy heat flux vanishes, in general, above the first model layer. The troposphere is coupled to the surface through exchange of latent, sensible and radiative heat fluxes between the surface and the boundary layer. As explained in Ramanathan (1981), the model explicitly computes the boundary layer relative humidity $\left(R H_{s}\right)$ and the latent heat release within the atmosphere such that the $\mathrm{H}_{2} \mathrm{O}$ balance equations are satisfied. The tropospheric relative humidity $\left(\mathrm{RH}_{z}\right)$ is computed using the relative humidity distribution function of Manabe and Wetherald (1967):

$$
\left(R H_{2}\right)=R H_{s}\left[\left(p / p_{s}\right)-0.02\right]
$$

where $p$ and $p_{s}$ are the atmospheric and surface pressures respectively. The typical vertical distribution of relative humidity given by this linear function is in good agreement with the hemispheric mean of relative humidity obtained by Telegadas and London (1954), Murgatroyd (1960) and Mastenbrook (1963). The model employs the moist adiabatic adjustment scheme wherein the critical lapse rate within each model layer is assumed to be the moist adiabatic lapse rate appropriate for the layer pressure 
and temperature. The effect of clouds is incorporated by adopting the equivalent single cloud model of Cess (1974). This equivalent single cloud represents a global average over many cloud layers. Adopting the three-layer cloud model of Manabe and Strickler (1964), and performing the averaging procedure suggested by Cess (1974), the threelevel clouds are replaced by a single cloud with cloud top altitude of $6.25 \mathrm{~km}$ and a fractional cloud cover of 0.45 .

The radiation model is similar to that described in Ramanathan and Dickinson (1979) with the following modifications: (i) inclusion of radiative effect of trace gases considered in the study, and (ii) use of pressure as a vertical coordinate so as to conserve mass automatically. The model includes radiative transfer processes such as pressure and doppler broadening, $\mathrm{H}_{2} \mathrm{O}$ continuum, hot and minor isotopic bands of $\mathrm{CO}_{2}$ and overlap of $\mathrm{H}_{2} \mathrm{O}$ continuum and rotation bands with $\mathrm{CO}_{2}$ and $\mathrm{O}_{3}$ bands. The model computes radiational cooling/heating due to $\mathrm{H}_{2} \mathrm{O}, \mathrm{CO}_{2}, \mathrm{O}_{3}$ and other optically active gases. The atmospheric distributions of carbon dioxide, ozone and other minor gases prescribed in the model are given in table 1. The trace constituents $\mathrm{N}_{2} \mathrm{O}, \mathrm{CH}_{4}, \mathrm{NH}_{3}$, $\mathrm{CF}_{2} \mathrm{Cl}_{2}$ and $\mathrm{CH}_{3} \mathrm{Cl}$ are assumed to be uniformly mixed with their respective abundances from ground to an altitude of $10 \mathrm{~km}$, while the constituents $\mathrm{C}_{2} \mathrm{H}_{4}$ and $\mathrm{SO}_{2}$ are assumed to be uniformly mixed from ground to an altitude of only $2 \mathrm{~km}$. Above these altitudes, the relative abundance of each of these trace gases decreases exponentially to a further $2 \mathrm{~km}$ height. These concentrations have been compiled from a variety of sources including observations and photo-chemical model results.

\section{Experiments on greenhouse effect of anthropogenic gases}

In our one-dimensional radiative-convective model, the atmosphere is allowed to attain radiative-convective equilibrium thermal structure for an initially prescribed global atmospheric composition. We first obtain a vertical steady-state temperature profile for the atmosphere containing the trace constituents with their present-day concentrations as listed in table 1 . Next, the concentration of one of the trace constituents is varied at a time from its present value to a two-fold increase and a new

Table 1. Concentrations of various atmospheric trace constituents prescribed in the model

\begin{tabular}{llll}
\hline & Constituent & \multicolumn{2}{c}{$\begin{array}{c}\text { Approximate present-day } \\
\text { concentration }\end{array}$} \\
\hline $\mathrm{CO}_{2}$ & abundance & 330 & $\mathrm{ppm} \mathrm{V}$ \\
$\mathrm{N}_{2} \mathrm{O}$ & abundance & 0.28 & $\mathrm{ppm} \mathrm{V}$ \\
$\mathrm{CH}_{4}$ & abundance & 1.60 & $\mathrm{ppm} \mathrm{V}$ \\
$\mathrm{NH}_{3}$ & abundance & $6 \times 10^{-3}$ & $\mathrm{ppm} \mathrm{V}$ \\
$\mathrm{CF}_{2} \mathrm{Cl}_{2}$ & abundance & $1 \times 10^{-4}$ & $\mathrm{ppm} \mathrm{V}$ \\
$\mathrm{CH}_{3} \mathrm{Cl}$ & abundance & $5 \times 10^{-4}$ & $\mathrm{ppm} \mathrm{V}$ \\
$\mathrm{SO}_{2}$ & abundance & $2 \times 10^{-3}$ & $\mathrm{ppm} \mathrm{V}$ \\
$\mathrm{C}_{2} \mathrm{H}_{4}$ & abundance & $2 \times 10^{-4}$ & $\mathrm{ppm} \mathrm{V}$ \\
$\mathrm{O}_{3}$ & column amount & 3.43 & $\mathrm{~mm} \mathrm{STP}$ \\
$\mathrm{NO}_{2}$ & column amount & $2 \times 10^{-3}$ & $\mathrm{~mm} \mathrm{STP}$ \\
$\mathrm{HNO}_{3}$ & column amount & $4.87 \times 10^{-3}$ & $\mathrm{~mm} \mathrm{STP}$ \\
& & & \\
\hline
\end{tabular}


vertical temperature profile is computed. We thus obtain the model computed changes in atmospheric thermal structure for perturbations in each of the atmospheric constituents.

Table 2 summarizes the surface temperature change due to doubling of the concentrations of each of the twelve atmospheric trace gases considered in the present study. Here, the doubling of the water vapour content is considered above $10 \mathrm{~km}$. Below this the $\mathrm{H}_{2} \mathrm{O}$ content is determined by the condition of fixed relative humidity. Our estimates of global surface warming for a two-fold increase in the trace gases suggest that the minor atmospheric constituents may have a significant effect on the earth's climate. The surface warming due to doubling of $\mathrm{CO}_{2}$ in the atmosphere is about $39 \%$ of the surface warming due to the combined effect of $\mathrm{CO}_{2}$ and other trace gases considered here. The surface warming due to doubling of water vapour concentration in the upper atmosphere is comparable to that due to the combined effect of other trace gases examined in this study excluding only the effects of $\mathrm{CO}_{2}$ and $\mathrm{O}_{3}$. The doubling of atmospheric ozone warms the earth's surface by $0.67^{\circ} \mathrm{K}$ which is about $15 \%$ of the total surface warming due to all trace constituents. The doubling of $\mathrm{N}_{2} \mathrm{O}$ concentration in the atmosphere leads to an increase in the mean temperature of the earth's surface by $0.5^{\circ} \mathrm{K}$, while the doubling of methane and ammonia concentrations brings about further temperature increases by 0.24 and $0.11^{\circ} \mathrm{K}$ respectively. The doubled concentration of freons $\left(\mathrm{CF}_{2} \mathrm{Cl}_{2}\right)$ results in a further additive greenhouse effect of about $0.02^{\circ} \mathrm{K}$.

Our calculations show further that the largest warming due to increase in atmospheric trace constituents occurs in the upper troposphere and not at the earth's surface. The moist adiabatic lapse rate formulation in our model produces $\mathrm{CO}_{2}$ induced warming of about $1.8^{\circ} \mathrm{K}$ at the surface and over $3^{\circ} \mathrm{K}$ in the upper troposphere. The temperature response to other constituents also increases with height at roughly the same rate as that of $\mathrm{CO}_{2}$ upto an altitude of about $8 \mathrm{~km}$ with a decreasing trend further upwards.

The above calculations are based on the assumption that the concentration of major

Table 2. Greenhouse effect due to doubling of various minor atmospheric constituents

\begin{tabular}{lc}
\hline Constituent & $\begin{array}{c}\text { Surface warming, } \\
T_{s}\left({ }^{\circ} \mathbf{K}\right)\end{array}$ \\
\hline $\mathrm{CO}_{2}$ & 1.78 \\
$\mathrm{H}_{2} \mathrm{O}$ & 1.07 \\
$\mathrm{O}_{3}$ & 0.67 \\
$\mathrm{~N}_{2} \mathrm{O}$ & 0.51 \\
$\mathrm{CH}_{4}$ & 0.24 \\
$\mathrm{NH}_{3}$ & 0.11 \\
$\mathrm{HNO}_{3}$ & 0.07 \\
$\mathrm{NO}_{2}$ & 0.03 \\
$\mathrm{CF}_{2} \mathrm{Cl}_{2}$ & 0.02 \\
$\mathrm{CH}_{3} \mathrm{Cl}$ & 0.01 \\
$\mathrm{C}_{2} \mathrm{H}_{4}$ & 0.01 \\
$\mathrm{SO}_{2}$ & 0.01 \\
\hline
\end{tabular}


atmospheric trace constituents considered in our study are potentially variable by factors of the order of two and the validity of this assumption is discussed in the following section.

\section{Scenario for future trends in concentration of atmospheric trace constituents}

We are aware that a warming of the earth's surface by $1^{\circ} \mathrm{K}$ or more may significantly alter the global atmospheric circulation patterns which could result in a general poleward shift of agro-climatic zones (NAS 1977). Today, radiatively and chemically active trace gases are being injected into the atmosphere at an alarmingly increasing rate by human activities. This necessitates the quantitative estimation of the increase in earth's mean surface temperature (greenhouse effect) due to perturbations in atmospheric constituents. Our results (described in the previous section) indicate that the anthropogenic perturbations of the atmospheric gaseous composition are likely to eventually warm the earth-atmosphere system. However, these estimates may be subject to a large range of uncertainties arising due to possible errors in estimates for natural sources and sinks for the trace gases and, further, due to the errors in projected future increase in their emission rates. Thus, in our attempts to predict the greenhouse effect of trace constituents on climate, the factors influencing the abundance of these trace gases should be properly understood.

Water vapour plays a predominent role in modulating atmospheric and surface temperatures and our results indicate that a substantial greenhouse effect results from doubling of stratospheric water vapour content. There is no justification to support the assumption of a fixed relative humidity condition for the stratosphere. The stratospheric water vapour abundance is largely controlled by towering cumulus clouds, major volcanic eruptions, fleets of supersonic aircraft and many other factors which make it difficult to precisely project the long-term potential variation of water vapour abundance in the stratosphere.

The upward trend of global atmospheric $\mathrm{CO}_{2}$ as a result of ever-increasing use of fossil fuels has been well-documented and projections of a global increase of the order of $100 \%$ by the year 2050 are probably reliable (wMo 1975). Beyond 2100, a peak atmospheric $\mathrm{CO}_{2}$ concentrations might reach 4 to 8 times the preindustrial level (NAS 1977). Thus, the atmospheric $\mathrm{CO}_{2}$ is likely to play a major role in future trends of the earth's radiation budget.

Recent studies (Fishman and Crutzen 1978) indicate that an appreciable fraction of tropospheric ozone is produced by photochemical oxidation of $\mathrm{CO}, \mathrm{CH}_{4}$ and other hydrocarbons in the presence of nitric oxide. These species have both biogenic and anthropogenic origin and, in addition, are synthesized within the troposphere by chemical processes. As pointed out by Ramanathan et al (1979), although the troposphere contains only $10 \%$ of the total atmospheric ozone, the IR opacity of tropospheric ozone is nearly the same as that of stratospheric ozone due to pressure broadening of the $9.6 \mu \mathrm{m}$ band. Photochemical modelling studies of Logan et al (1978), Fishman et al (1979) and Hameed et al (1980) estimate that if the present growth rate of emission of various hydrocarbons is continued into the next century, the tropospheric ozone may double its present value.

The extensive use of nitrogen fertilizers provides the primary mechanism for the 
perturbation in atmospheric $\mathrm{N}_{2} \mathrm{O}$ concentration. A large range of predictions of chemical modellers suggests that the atmospheric $\mathrm{N}_{2} \mathrm{O}$ concentration may increase by as much as a factor of two by the year 2020. Probably the source of $\mathrm{NH}_{3}$ would scale with that of $\mathrm{N}_{2} \mathrm{O}$ and hence we would anticipate a potential increase in $\mathrm{NH}_{3}$ of the same magnitude as that for $\mathrm{N}_{2} \mathrm{O}$.

The atmospheric concentrations of $\mathrm{CH}_{4}, \mathrm{C}_{2} \mathrm{H}_{4}$ and $\mathrm{CH}_{3} \mathrm{Cl}$ have increased in recent decades as a result of increased anaerobic decay processes and the decay of marine biological organisms. An increase in atmospheric $\mathrm{HNO}_{3}$ is unavoidable due to the speedup of the nitrogen cycle. Combustion together with oxidation processes is responsible for the buildup of $\mathrm{SO}_{2}$ in the atmosphere. The future projections of these gases in the atmosphere are difficult to assess and for our study here we have assumed that these gases are potentially variable by factors of the order of two.

The freons $\left(\mathrm{CF}_{2} \mathrm{Cl}_{2}\right)$ seems to have a considerable influence on the infrared transparency of the atmosphere (Ramanathan 1975). The atmospheric concentrations of freons may increase by as much as 20 to 30 times if the present level of injection into the atmosphere is maintained (Molina and Rowland 1974). The primary reason for this expected buildup seems to be the lack of any significant tropospheric removal mechanism. The freons have a characteristic lifetime in the atmosphere of the order of 10 years. The changes in the greenhouse effect caused by freons may therefore influence the earth's climate more notably than those die to other trace constituents.

The above discussions highlight the need for accurate monitoring of the global trends in the concentration of atmospheric trace gases in any attempt to understand and predict man's impact on climate through the greenhouse effect. In this study, we have excluded the potential counter-role of aerosols which is important for a reliable climate prognostication.

\section{Conclusions}

This paper mainly presents the changes in the surface temperature of the earth for large assumed increases in the atmospheric trace gases. Though the surface warming due to abundance of a particular constituent may appear negligible, the combined greenhouse effect of minor atmospheric constituents is mostly additive and thus it may have a substantial effect on the earth's climate.

Since anthropogenic changes in the composition of the atmosphere are several, their influence on the greenhouse effect and climate must take into account all vital constituents and in this respect, our findings in table 2 may serve as a reference. The global trend of atmospheric trace constituents may undergo substantial non-linear changes in abundance. This necessitates a detailed study of the prediction of atmospheric chemical evolution. For more realistic appraisal of future climatic impact of atmospheric trace gases, account must be taken of the atmospheric dynamics and interaction of continuous changes in the composition of the atmosphere.

\section{Acknowledgements}

The authors are indebted to Dr V Ramanathan for providing his model and educating us on various aspects of this study. The computer facilities provided by the National Informatics Centre, New Delhi, are gratefully acknowledged. 


\section{References}

Cess R D 1974 J. Quant. Spectrosc. Radiat. Transfer 14861

Fishman $J$ and Crutzen $P$ J 1978 Nature 274855

Fishman J, Ramanathan V, Crutzen P J and Liu S C 1979 Nature (London) 282818

Hameed S, Cess R D and Hogan J S 1980 J. Geophys. Res. 857537

Lal $M$ and Ramanathan V 1984 J. Atmos. Sci. 412238

Logan J A, Prather M J, Wofsy S C and McElroy M B 1978 Trans. R. Soc. 290187

Manabe S and Strickler R F $1964 \mathrm{~J}$. Atmos. Sci. 21361

Manabe S and Wetherald R T 1967 J. Atmos. Sci. 24241

Mastenbrook H J 1963 Humidity and moisture (New York: Reinhold) Vol. 2, p. 480

Molina M J and Rowland F S 1974 Nature (London) 249810

Murgatroyd R J 1960 Proc. Symp. Atmos. Ozone, Oxford July 1959 IUGg Monograph No. 3, (Paris: IUGG Publications Office) p. 30

NAS 1977 Energy and climate, (Washington, DC: National Academy of Sciences)

Ramanathan V 1975 Science 19050

Ramanathan V and Dickinson R E 1979 J. Atmos. Sci. 361084

Ramanathan V 1981 J. Atmos. Sci 38918

Telegadas K and London J 1954 Sci. Rep. No. 1, Contract AF 19(122)-165, Res. Div., College of Engg., New York Univ., 52 pp.

WMO (World Meteorological Organisation) 1975 GARP Pub. 16, Geneva, Switzerland 